3. Rutala WA, Weber DJ. Disinfectants used for environmental disinfection and new room decontamination technology. Am J Infect Control 2013;41:S36-S41.

4. Rutala WA, Gergen MF, Weber DJ. Room decontamination by ultraviolet radiation. Infect Control Hosp Epidemiol 2010;31:10251029.

5. Anderson DJ, Gergen MF, Smathers E, et al. Decontamination of targeted pathogens from patient rooms using an automated ultraviolet-C-emitting device. Infect Control Hosp Epidemiol 2013; 34:465-471.

6. Boyce JM, Havill NL, Moore BA. Terminal decontamination of patient rooms using an automated mobile UV light unit. Infect Control Hosp Epidemiol 2011;32:743-747.

7. Nerandzic MM, Cadnum JL, Pultz MJ, Donskey CJ. Evaluation of an automated ultraviolet radiation device for decontamination of Clostridium difficile and other healthcare-associated pathogens in hospital rooms. BMC Infect Dis 2010;10:197.

8. Rutala WA, Gergen MF, Tande BM, Weber DJ. Rapid hospital room decontamination using ultraviolet (UV) light with a nanostructured UV-reflective wall coating. Infect Control Hosp Epidemiol 2013;34:527-529.

\section{Brucella abortus Exposure during an Orthopedic Surgical Procedure in New Mexico, 2010}

Brucellosis, a zoonotic disease that can be transmitted through inhalation of infectious aerosolized particles, is endemic in many areas, including Mexico. ${ }^{1-4}$ Manifestations of disease can range from subclinical illness to osteoarticular disease and chronic sequelae. ${ }^{4}$ It is a potential occupational hazard among laboratory workers. ${ }^{3}$ Although Brucella infection is not usually a risk to medical staff, prosthetic joint infections have been encountered during surgery. ${ }^{5-9}$ We report a case of periprosthetic Brucella infection and the subsequent investigation into possible transmission to operating room and laboratory staff. Objectives of the investigation included infection prevention, case-finding, and examination into potential routes of Brucella species transmission.

The New Mexico Department of Health (NMDOH), in consultation with the Centers for Disease Control and Prevention (CDC), initiated an investigation of operating room and laboratory staff exposures. Among operating room staff, high-risk exposures were defined as presence in the operating room during aerosol-generating procedures, including joint irrigation and cleaning after the procedure. $\mathrm{NMDOH}$ Scientific Laboratory Division and reference laboratory staff involved in testing the patient's isolate were contacted to evaluate laboratory exposures. Serial serologic testing and antibiotic postexposure prophylaxis (PEP; $100 \mathrm{mg}$ doxycycline orally twice daily and rifampin $600 \mathrm{mg}$ once daily for 21 days, for those without contraindications) was recommended for individuals with high-risk exposures. ${ }^{10}$ The CDC performed serologic testing for anti-Brucella antibodies by microagglutination.

The 67-year-old female patient was born in, raised in, and frequently traveled to Mexico. Her first hip replacement occurred in Mexico 2 years before presentation for revision. During revision, implant component loosening, bone loss, and cloudy synovial fluid were noted. Synovial fluid was cultured, the joint was debrided and copiously irrigated, and hip replacement was deferred; an articulating vancomycinand tobramycin-impregnated cement spacer was placed. Growth suggestive of Brucella species resulted from synovial fluid culture at a reference laboratory. The NMDOH Scientific Laboratory Division conducted confirmatory nucleic acid amplification testing, and subsequently the CDC performed speciation; Brucella abortus was identified.

Seventeen high-risk exposures and 1 low-risk exposure were investigated; fifteen high-risk exposures occurred in the operating room. Personal protective equipment (PPE) varied from body exhaust suits (surgeon, first assistant, and scrub technician) to gloves only (cleaning staff); none wore N95 respiratory protection. Because the joint was copiously irrigated, hospital staff who cleaned the operating room were also considered to be exposed. One low- and 2 high-risk reference laboratory staff exposures occurred during isolate processing outside of the biosafety cabinet on an open bench; the low-risk exposure occurred outside the 5 -foot $(1.5-\mathrm{m})$ radius for exposures that qualified as high risk. ${ }^{10}$ No exposures occurred at the NMDOH Scientific Laboratory Division, because the isolate was handled inside a biosafety cabinet.

Fifteen exposed operating room staff underwent serial serologic testing and prophylaxis. Reference laboratory employees with high-risk exposures agreed to serologic testing but declined PEP. All who elected prophylaxis completed the PEP regimen. None of those exposed met criteria for seroconversion (ie, fourfold increase in anti-Brucella antibody titer). Two individuals whose total antibody titers were indeterminate (between $1: 20$ and $1: 40$, potentially resulting from test run variation and assay cross-reaction with other antibodies) were referred for infectious disease consultation; no evidence of acute Brucella infection was detected. Exposed individuals self-monitored and were observed by personal healthcare or occupational medicine providers for 6 months; none developed symptoms of brucellosis.

The surgical patient was treated for 3 months with combination therapy (doxycycline and rifampin) to address osteomyelitis and prevent Brucella infection relapse. A preoperative aspirate, before reimplantation of the hip replacement, yielded a negative culture result. The $\mathrm{NMDOH}$ recommended that anyone involved in reimplantation use N95 masks and goggles, minimize aerosol-generating procedures, and handle biological specimens with care. The patient's recovery was uneventful without evidence of infection recurrence at 2 years of follow-up.

This case report demonstrates the need to consider evaluation for Brucella species infection and risk factors among 
patients with prostheses failure or osteoarticular prosthetic infections. Although there are not any documented instances of Brucella transmission during surgery, repeated instances of laboratory transmission support a precautionary approach. During prosthetic joint arthroplasty procedures, surgical staff may wear orthopedic space suits or a mask and face shield to protect themselves from bloodborne pathogen transmission through droplet sprays; additional respiratory protection may be needed to protect staff from airborne transmission of aerosolized pathogens. As in this case, postoperative brucellosis diagnosis after surgery for an infected joint warrants an evaluation of PPE appropriateness and potential breaches. Personnel who did not wear or experienced a breach in PPE should be monitored with serologic testing for 6 months and report new symptoms consistent with brucellosis. PEP may be considered if the procedure aerosolized the Brucella organism.

If preoperative patient evaluation identifies Brucella species infection, appropriate antibiotic therapy can be initiated to decrease bacterial load in surrounding tissues, and precautions can be taken to limit surgical Brucella species exposure. Surgeons and operating room staff should wear appropriate respiratory PPE (ie, N95 mask), minimize aerosol-generating procedures, and only essential operating room personnel should be present. Regardless of PPE worn, personnel present during the procedure should be considered for 6 months of symptom monitoring because of potential unrecognized aerosol exposures and PPE breaches.

Although rare in those countries where it is nonendemic, brucellosis osteoarticular infections occur and pose a potential risk to surgeons and other operating room staff. Therefore, recommendations similar to the guidelines for accidental Brucella species laboratory exposures are needed to standardize PPE use, prevent transmission of brucellosis during surgical procedures, and provide information regarding symptom and serologic monitoring as well as administration of PEP.

\section{ACKNOWLEDGMENTS}

Potential conflicts of interest. All authors report no conflicts of interest relevant to this article. All authors submitted the ICMJE Form for Disclosure of Potential Conflicts of Interest, and the conflicts that the editors consider relevant to this article are disclosed here.

\author{
Megin Nichols, DVM, MPH; ${ }^{1}$ \\ Deborah Thompson, MD, MSPH; ${ }^{1}$ \\ Joshua T. Carothers, MD; ${ }^{2}$ Judy Klauber, $\mathrm{BS}^{3}$ \\ Robyn A. Stoddard, DVM, PhD; ${ }^{4}$ \\ Marta A. Guerra, DVM, MPH, PhD; ${ }^{4}$ \\ Tina J. Benoit, MPH; ${ }^{4}$ Rita M. Traxler, $\mathrm{MHS}^{4}$
}

Affiliations: 1. New Mexico Department of Health, Epidemiology and Response Division, Santa Fe, New Mexico; 2. New Mexico Orthopedics, Albuquerque, New Mexico; 3. New Mexico Department of Health, Scientific Laboratory Division, Albuquerque, New Mexico; 4. Centers for Disease Control and Prevention, Division of High-Consequence Pathogens and Pathology, National Center for Emerging and Zoonotic Infections, Atlanta, Georgia.

Address correspondence to Megin Nichols, DVM, MPH, New Mexico Department of Health, 1190 St. Francis Drive, Suite N-1350, Santa Fe, NM 87505 (megin.nichols@state.nm.us).

Received December 26, 2013; accepted March 19, 2014; electronically published June 20, 2014.

Infect Control Hosp Epidemiol 2014;35(8):1072-1073

(C) 2014 by The Society for Healthcare Epidemiology of America. All rights reserved. 0899-823X/2014/3508-0024\$15.00. DOI: $10.1086 / 677155$

\section{REFERENCES}

1. Pappas G, Papadimitriou P, Akritidis N, Christou L, Tsianos EV. The new global map of human brucellosis. Lancet Infect Dis 2006;6:91-99.

2. Luna-Martinez JE, Mejia-Teran C. Brucellosis in Mexico: current status and trends. Vet Microbiol 2002;90:19-30.

3. Pappas G, Akritidis N, Bosilkovski M, Tsianos E. Brucellosis. N Engl J Med 2005;352:2325-2336.

4. Franco MP, Mulder M, Gilman RH, Smits HL. Human brucellosis. Lancet Infect Dis 2007;7:775-786.

5. Erdogan H, Cakmak G, Erdogan A, Arslan H. Brucella melitensis infection in total knee arthroplasty: a case report. Knee Surg Sports Traumatol Arthrosc 2010;18(7):908-910.

6. Ruiz-Iban MA, Crespo P, Diaz-Peletier R, Rozado AM, LopezPardo A. Total hip arthroplasty infected by Brucella: a report of two cases. J Orthop Surg (Hong Kong) 2006;14:99-103.

7. Weil Y, Mattan Y, Liebergall M, Rahav G. Brucella prosthetic joint infection: a report of 3 cases and a review of the literature. Clin Infect Dis 2003;36:e81-e86.

8. Kasim RA, Araj GF, Afeiche NE, Tabbarah ZA. Brucella infection in total hip replacement: case report and review of the literature. Scand J Infect Dis 2004;36:65-67.

9. Tena D, Romanillos O, Rodriguez-Zapata M, et al. Prosthetic hip infection due to Brucella melitensis: case report and literature review. Diagn Microbiol Infect Dis 2007;58:481-485.

10. Centers for Disease Control and Prevention. Laboratoryacquired brucellosis-Indiana and Minnesota, 2006. MMWR Morb Mortal Wkly Rep 2008;57:39-42. 